\title{
Estimating Corrosion Initiation Period Due to Chloride Ingress into Reinforced Self- Compacting Concrete Incorporating High Volume Fly Ash
}

\author{
Stefanus Kristiawan ${ }^{1, *}$, Wibowo ${ }^{1}$, Sunarmasto ${ }^{1}$, Buntara $S$ Gan $^{2}$ and Septina Nurrohmah ${ }^{1}$ \\ ${ }^{1}$ SMARTCrete Research Group, Civil Engineering Department, Sebelas Maret University, Jl. Ir. \\ Sutami No. 36A Surakarta 57126, Indonesia \\ ${ }^{2}$ Department of Architecture, College of Engineering, Nihon University, Koriyama, Japan
}

\begin{abstract}
One of the main sources of reinforcement corrosion is the ingress of chloride ion into a concrete structure. The rate of chloride ingress and its consequence to initiate corrosion could determine the service life of the structure. This paper aims to estimate the corrosion initiation period of reinforced self-compacting concrete incorporating high volume fly ash. The governing equation whih characterize the chloride ingress through ionic diffusion is numerically solved using finite difference method. The numerical solutions are used to assess the influence of fly ash content, concrete cover and temperature on the time of corrosion initiation.
\end{abstract}

\section{Introduction}

Service life of structure is an important aspect that should be taken into account in the design process. A structure must be designed in such a way to achieve an economical structure at an acceptable reliability throughout its service life in accordance with the needs of the user. The reliability must cover all types of actions that may arise during the expected service life of the structure. These provisions must be met by means of suitable material selection, appropriate design method and detailing, and proper control of design process, production, execution and use [1]. In an attempt to meet the requirements, it is necessary to have a fundamental understanding of the factors that predominantly influence the service life of the structure.

The influencing parameters that determine the service life of structure may be governed by the rate of material degradation. In the case of reinforced concrete structure, the degradation rate could be related to the ingress of aggressive agents from the environment surrounding the concrete structure. Thus, the type of aggressive agents and their concentration are among those of the determinant factors. The degradation rate also depends on the quality of the concrete itself, especially the porosity/permeability of concrete. Taking into account these two factors (environment and concrete quality), many design Codes provide a clause regarding the environmental classification and its

* Corresponding author: s.a.kristiawan@ft.uns.ac.id 
corresponding proportion of concrete to satisfy the performance. This clause indicates that the method used to meet the service life requirement is a prescriptive approach [2,3].

The prescriptive approach is developed on the basis of available data of performance of existing structures. This approach has a limitation in its application when new material is introduced since there are no reference data for such material. The limitation encourages designer to move toward the performance-based approach [4-5]. Many researches have been carried out to develop performance-based method for estimating service life of structure by considering particular environmental action, for example chloride ingress into concrete [6-10]. The basic principle of the method is to estimate the service life as the sum of the corrosion initiation and propagation period. The initiation period is the time required for chloride ions to penetrate into the body of concrete and reach a critical concentration at the surface of the embedded reinforcement which could initiate corrosion. The propapation period corresponds to the degradation that follows until the limit state is attained beyond which structure will fail.

The mechanisms by which aggressive ions may penetrate into concrete could be due to one or combination of the following ionic transport mechanisms [10]: pressure-induced water flow, water absorption, water vapour diffusion, wick action, ion diffusion, gas diffusion and pressure-induced gas flow. For chloride ions transport, the predominant mechanism is thought to be the ionic diffusion. Hence, the performance-based methods for estimating corrosion initiation are developed on the basis of calculating chloride ions diffusion causing corrosion initiation. The chloride ions diffusion is governed by the Fick's second law as follows:

$$
\frac{\partial C(x, t)}{\partial t}=D \frac{\partial^{2} C(x, t)}{\partial x^{2}}
$$

where $x, t, c(x, t)$ and $D$ represents depth of chloride penetration, time, concentration of chloride ion at depth $x$ and time $t$, and chloride ion diffusion coefficient of concrete, respectively. The boundary conditions for solving Equation (1) is:

$$
C(x, t)\left\{\begin{array}{l}
C_{S} \text { if } x=0 \\
C o \text { if } x \approx \infty
\end{array}\right.
$$

where $c_{O}$ and $c_{S}$ is an initial concentration of chloride ion in the body of concrete and concentration of chloride ion at the concrete surface, respectively. Assuming homogenous diffusion of concrete property, solution of Equation (1) with boundary condition as in Equation (2) gives:

$$
\frac{C_{S}-C(x, t)}{C_{S}-C_{o}}=\operatorname{erf}\left(\frac{x}{2 \sqrt{D t}}\right)
$$

Equation (3) may be used to estimate the corrosion initiation by substituting $x$ with the depth of embedded reinforcement and $c(x, t)$ with the critical chloride concentration $\left(c_{c r}\right)$.

Sun et al. [11] confirmed that it may not appropriate to assume a homogenous characteristic of concrete diffusion along its depth. In fact, many factors affect the ionic transport properties of chloride into concrete i.e. reactivity of chloride ion and its chemical bound with the cement paste constituent, the time dependent property of concrete, the temperature of the environment, etc. Hence, Equation (3) may not correctly predict the corrosion initiation. Adjustment of Equation (1) is, therefore, necessary to accommodate any factors influencing the ionic transport properties of chloride into concrete. Consequently, the exact solution of Equation (1) will not easily be determined. For this 
reason, numerical solution could be introduced to properly describe the complex ionic transport behaviour. With numerical solution, concrete is divided into several layers along its depth. Initial boundary conditions and any factors affecting the transport properties of the chloride ions could be assigned for each discrete element. An example of such solution is that of Life-365 software, which has been developed for estimating service life of reinforced concrete due to chloride ingress [12]. The software capable to predict the effect of various factors either environmental conditions or concrete ingredients on the service life of reinforced concrete structure. However, the software is not suitable to be used for estimating special type of concrete which is not covered by its database. This paper aims to provide numerical solution for estimating corrosion initiation of special type of concrete i.e. self-compacting concrete incorporating high volume fly ash. The high volume fly ash is defined by the replacement level of cement with fly ash where at least $50 \%$ (by weight of total binder) of fly ash is introduced. This special type of concrete is then termed as high volume fly ash-self compacting concrete (HVFA-SCC). The finite difference method is chosen to obtain the numerical solution of Equation (1). The results could be used to estimate the influence fly ash content on the corrosion initiation period of HVFA-SCC. The numerical solution is extended to include the influence of concrete cover and temperature on the corrosion initiation period of the said concrete.

\section{Numerical solution with finite difference method}

The finite difference formulation of Equation (1) is given as follows:

$$
C(t+\Delta t)=C(t)+\left(D \frac{C(x+\Delta x)-2 C(x)+C(x-\Delta x)}{\Delta x^{2}}\right) \Delta t
$$

The influence of the temperature on the coefficient diffusion $D$ is taken into account in the current research by adopting the relation as that of Life-365 model. The influence of fly ash is inserted in the relation as follows:

$$
D_{f G(T)}=D_{\text {ref }} \cdot F A \cdot \exp \left[\frac{v}{R} \cdot\left(\frac{1}{\tau_{r e f}}-\frac{1}{\tau}\right)\right]
$$

where $D_{f a(T)}$ is coefficient diffusion of HVFA-SCC with fly ash content $f a$ at absolute temperature $T(\mathrm{~K})$. Meanwhile, $D_{\text {ref }}$ and $T_{\text {ref }}$ is reference coefficient diffusion and reference temperature, respectively. For the current research, the $D_{\text {ref }}$ is represented by $D_{50(293)}$ i.e. the coefficient diffusion of HVFA-SCC with 50\% fly ash content determined at $T_{\text {ref }}$ about 293 $\mathrm{K}\left(20^{\circ} \mathrm{C}\right) . U$ is activation energy of the diffusion process $(35000 \mathrm{~J} / \mathrm{mol})$ and $R$ is gas constant $(8.314472 \mathrm{~J} / \mathrm{mol} . \mathrm{K}) . F A$ is ratio of coefficient diffusion of HVFA-SCC at fly ash content higher than $50 \%$ to that of $D_{\text {ref. }}$. Hence, its value is 1 for HVFA-SCC with fly ash content $50 \%$. For HVFA-SCC with higher fly ash content (more than 50\%), Equation (6) may be used to substitute $F A$ of Equation (5).

$$
F A=0.00014 f a^{3}-0.0242 f a^{2}+1.351 f a-23.8
$$

Equation (6) is derived using data from [13]. The basic mixture of SCC used in this reference was $738 \mathrm{~kg}$ of cement, 579 and $703 \mathrm{~kg}$ of fine and course aggregate, respectively, $211 \mathrm{~kg}$ of water and $7.27 \mathrm{~kg}$ of superplasticizer as per $\mathrm{m}^{3}$. Fly ash contents in the range of $50-70 \%$ were introduced to partially substitute cement. The chloride profiles of SCC with various fly ash contents were determined by salt ponding test as specified in AASHTO 
T259 where the surface of HVFA-SCCs were exposed to solution of 3\% NaCl. This test was carried out under laboratory environment. After 90 days period of exposure, the amount of chloride ingress into HVFA-SCCs were determined along the depth of the penetrations. These chloride profiles were then analyzed to obtain coefficient diffusions and concentrations of chloride ion at the surface of concrete (Cs) shown in Table 1 [13]. The relationship of ratio of coefficient diffusion of HVFA-SCC with fly ash content more than $50 \%$ to $D_{\text {eff }}$ i.e. $F A$ versus fly ash content $f a$ could be established by regression analysis (Fig. 1) resulting in Equation (6).

Table 1. Coefficient diffusion of HVFA-SCC and $C s$ value at various fly ash contents.

\begin{tabular}{|l|c|c|c|c|c|}
\hline Fly ash content & $\mathbf{5 0} \%$ & $\mathbf{5 5} \%$ & $\mathbf{6 0} \%$ & $\mathbf{6 5} \%$ & $\mathbf{7 0} \%$ \\
\hline Coefficient diffusion $\left(\mathrm{m}^{2} / \mathrm{s}\right)$ & $2.20 \mathrm{E}-12$ & $1.98 \mathrm{E}-12$ & $1.90 \mathrm{E}-12$ & $1.70 \mathrm{E}-12$ & $2.10 \mathrm{E}-12$ \\
\hline$C s(\%$ by weight of concrete) & 0.9963 & 0.9024 & 0.8229 & 0.8064 & 0.8735 \\
\hline
\end{tabular}

\begin{tabular}{|c|}
\hline Renuls \\
\hline Linear model Poly 3 \\
\hline$f(x)=p_{1} *_{x}^{\wedge} 3+t_{p} \dot{*}^{\wedge} 2+_{p} 3 *_{x}+t_{p}^{4}$ \\
\hline Coefficient (with $90 \%$ confident bounds) \\
\hline $\mathrm{p}^{1}=0.0001426(0.0001357,0.0001495)$ \\
\hline $\mathrm{p}^{2}=-0.02423(-0.02547,-0.02299)$ \\
\hline $\mathrm{p}^{3}=1.351(1.277,1.425)$ \\
\hline $\mathrm{P}^{4}=-23.81(-25.28,-22.34)$ \\
\hline Goodness of fit: \\
\hline SSE: 0.0001134 \\
\hline R-square: 0.9989 \\
\hline Adjusted R-square: 0.9987 \\
\hline RMSE: 0.002583 \\
\hline
\end{tabular}

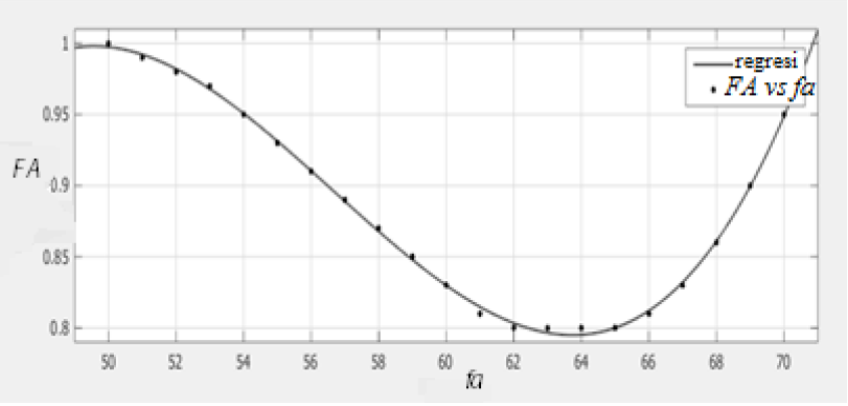

Fig. 1. Relationship of $F A$ and $f a$.

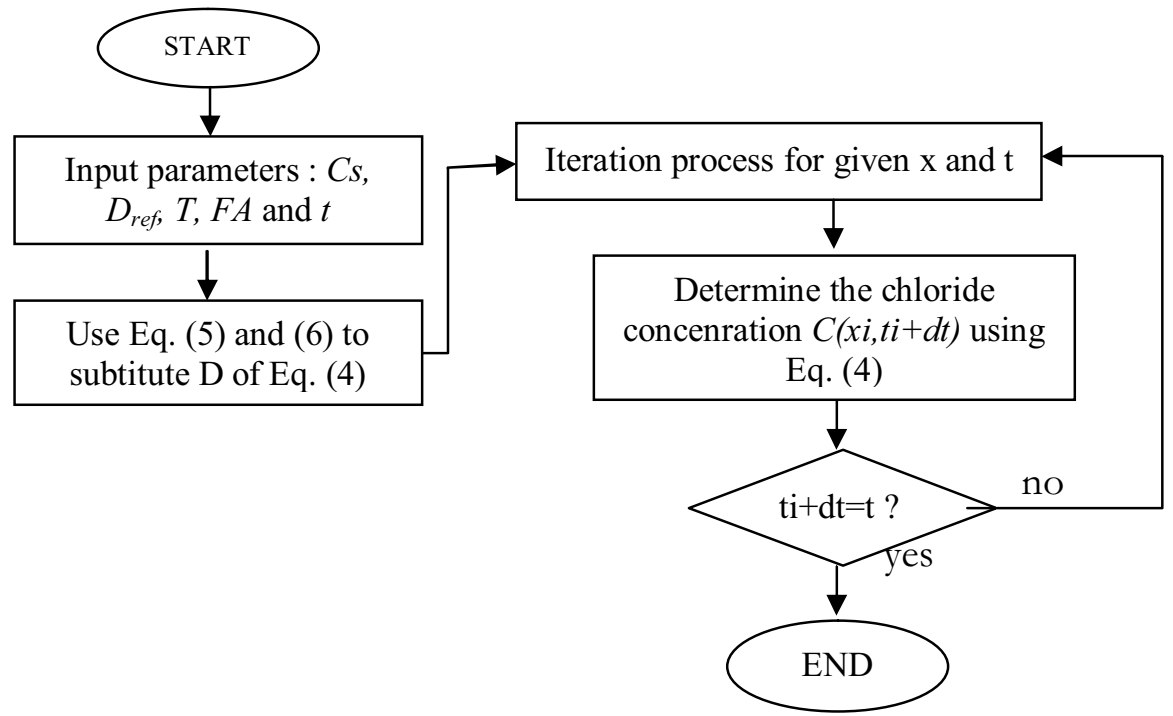

Fig. 2. Flowchart of numerical solution procedure. 


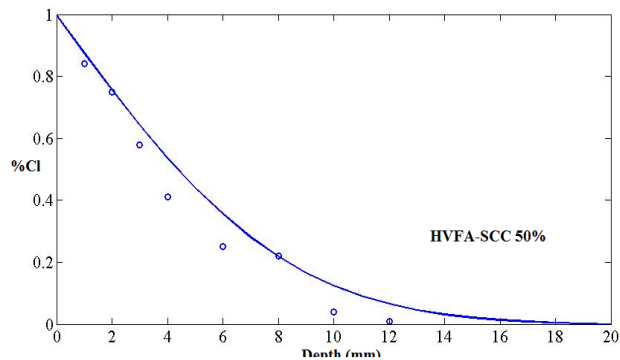

(a)

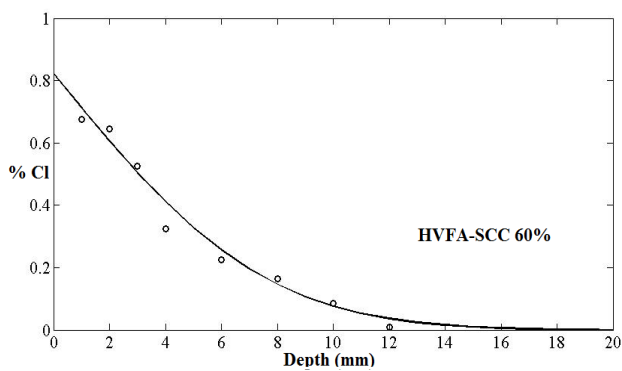

(c)

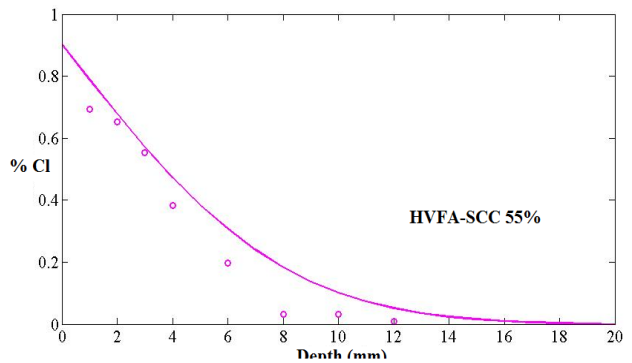

(b)

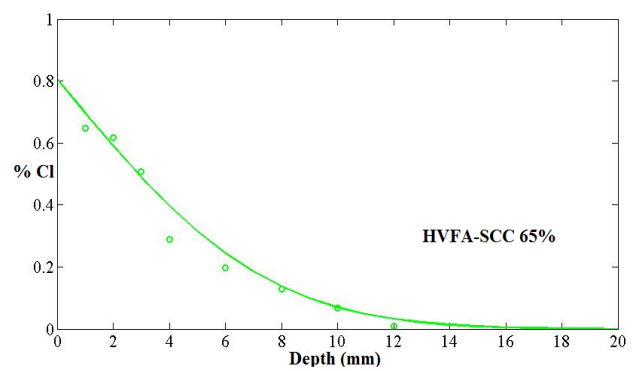

(d)

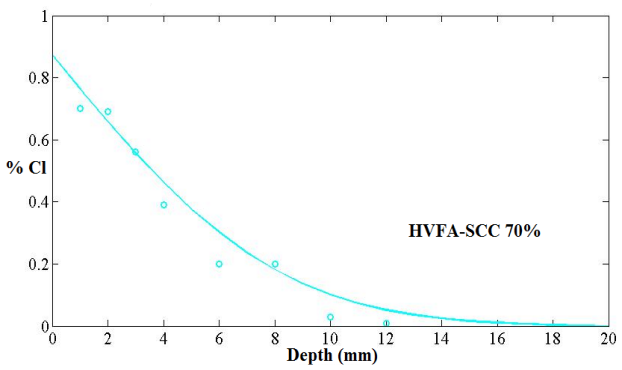

(e)

Fig. 3. Comparison of the numerical solution (line) and the experimental data of chloride profiles (dots) for HVFA-SCC with various fly ash contents.

Fig. 2 shows the procedure for obtaining the numerical solution of Equation (4). The required input parameters are $D_{r e f}, C s, T, t$ and $f a$. The value of $C s$ refers to Table 1 . With the given input parameters, the first step is to substitute $F A$ of Equation (5) with Equation (6) and then uses the $D_{f a(T)}$ of Equation (5) to substitute the coefficient diffusion $D$ of Equation (4). Iteration process is carried out to evaluate Equation (4) for given $x$ and $t$.

The results of numerical solution are validated with the experimental data of chloride profiles from [13] as shown in Fig. 3. Generally, it can be conveniently concluded that a good agreement exists between the results of numerical solution and the experimental data.

\section{Estimating the corrosion initiation of HVFA-SCC}

The numerical solution by finite difference method as described in the previous section is now applied to estimate the corrosion initiation period of HVFA-SCC. The critical chloride concentration $\left(c_{c r}\right)$ which could possibly initiate the corrosion is in the range of 0.4-1.0\% by weight of cement (or $0.06-0.3 \%$ by weight of concrete) [14]. For this study, $c_{c r}$ is assumed to be $0.06 \%$ by weight of concrete. The embedded reinforcement is given at a 
distance of $50 \mathrm{~mm}$ from the concrete surface. The environmental condition is represented by the value of chloride concentration at the surface of concrete $(\mathrm{Cs})$, where in this case is assumed to be $0.2 \%$ by weight of concrete. This value is taken to represent a typical temperate climate marine environment [15]. In reality, there is a period which is required for the chloride concentration to reach its maximum concentration at the concrete surface. The period to build to maximum concentration is omitted in this simulation. Hence, the estimated corrosion initiation of this simulation is based on assumption that $C s$ occurs instantly. Fig. 4. (a) shows the influence of fly ash content on the time of corrosion initiation. Increasing fly ash content from $50 \%$ to $60 \%$ could prolong the initiation period at about 3 years. The figure also clearly illustrates an optimum fly ash content of $64 \%$ that will provide the longest corrosion initiation.

Fig. 4.(b) illustrates the influence of concrete cover on the time of corrosion initiation of HVFA-SCC with fly ash content of $50 \%$. This figure provides a good indication of the important of concrete cover to protect the embedded reinforcement. The effect of increasing concrete cover is to prolong the corrosion initiation period at an accelerating rate. For examples, if concrete cover is inceased by $10 \mathrm{~mm}$ from its original value of $40 \mathrm{~mm}$, the corrosion initiation is prolonged by 5 years. Further increase of $10 \mathrm{~mm}$ will give an additional 7 years of corrosion initiation period.

The effect of temperature on the corrosion initiation period of HVFA-SCC with fly ash content of 50\% is illustrated in Fig. 4. (c). The concrete cover used for this simulation is 40 $\mathrm{mm}$. The figure clearly shows that an increase of environment temperature from $25^{\circ} \mathrm{C}$ to $35^{\circ} \mathrm{C}$ will reduce the corrosion initiation from 14 years to 9 years.

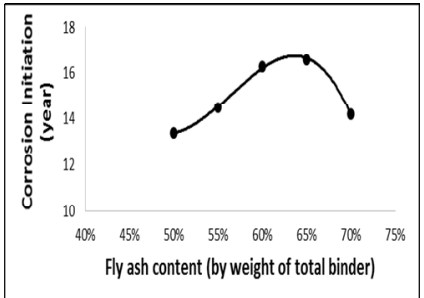

(a) fly ash content

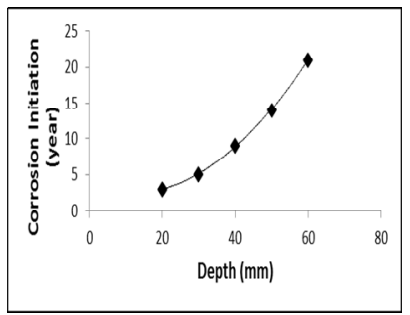

(b) depth of concrete cover

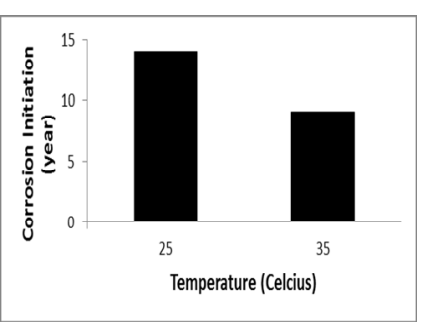

(c) temperature

Fig. 4. Effect of various parameters on corrosion initiation period of HVFA-SCC.

\section{Conclusions}

Numerical solution by finite difference method has been adopted to characterize chloride ion diffusion into self-compacting concrete incorporating high volume fly ash. Generally, a good agreement exists between the results of numerical solution and the experimental data. The numerical solutions are then applied to estimate the corrosion initiation period of mentioned concrete and assess the influence of fly ash content, concrete cover and temperature. The optimum fly ash content which yields the longest corrosion initiation period is about $64 \%$. It is also found that concrete cover is essential to protect the embedded reinforcement. An increase of concrete cover will prolong the corrosion initiation period at accelerating rate. Higher temperature will decrease corrosion initiation period.

\section{References}

[1] Eurocode 1 General actions-Part 1-1: Densities, self-weight, imposed loads for buildings, British Standard, London, United Kingdom, (2002) 
[2] Eurocode 2 General actions-Part 1-1: Design of concrete structures, British Standard, London, United Kingdom, (2004)

[3] Eurocode 1 General actions-Part 1: Specification, performance, production and Conformity, British Standard, London, United Kingdom, (2000)

[4] International Federation for Structural Concrete (fib), Bulletin 34: Model code for service life design, the International Federation for Structural Concrete ( $f i b)$, Lausanne, Switzerland, (2006)

[5] International Federation for Structural Concrete (fib), Model code for concrete structures 2010, Wilhelm Ernst \& Sohn, Rotherstraße 21, 10245 Berlin, (2013)

[6] I. Khan, R. Francois and Castel, Cem. Conc. Res. 56, 84 (2014)

[7] U. Angst, A. Ronnquist, B. Elsener, S.K. Larsen and O. Vennesland, Corr. Sci. 53,177 (2011)

[8] U. Angst, B. Elsener, C.K. Larsen and O. Vennesland, Corr. Sci. 53, 1451 (2011)

[9] U. Angst, B. Elsener, C.K. Larsen and O. Vennesland, Electrocimica Acta 56, 5877 (2011)

[10] R.M. Ferrera, Probability-based durability analysis of concrete structures in marine environment (PhD Thesis, University of Minho, Portugal, (2004)

[11] Sun G, Zhang Y, Sun W, Liu Z, and Wang C, Constr. Build. Mat. 25 (10), (2011)

[12] M.A. Ehlen, Life-365 ${ }^{T M}$ Service Life Prediction Model ${ }^{T M}$ and Computer Program for Predicting the Service Life and Life-Cycle Cost of Reinforced Concrete Exposed to Chlorides Version 2.2, Life 365TM Consortium III, USA, (2014)

[13] S.A. Kristiawan, S. As'ad, Wibowo, B.S. Gan, D.P. and Sitompul, Effect of high volume fly ash on the chloride penetration resistance of Self-Compacting Concrete (SCC), Advances in Civil, Architectural, Structural and Constructional Engineering. CRCPress, 31-34, (2016)

[14]G. Markeset and O. Vennesland, Critical chloride content in reinforced concrete, COIN Project Report 6, SINTEF Building and Infrastructure, Oslo, Norway, (2009)

[15] A. Costa and J. Appleton, Mat. Struc. 32, 354 (1999) 